\title{
Mudanças econômicas e possibilidades dos territórios: observações sobre a trajetória recente do oeste de Santa Catarina
}

Hoyêdo Nunes Lins ${ }^{*}$

\section{Resumo}

O plano local ou regional se destacou nas últimas décadas na promoção do desenvolvimento, por conta de mudanças seja na atuação do Estado, pela descentralização de algumas de suas funções, seja na produção industrial, pelo reconhecimento do papel que os atributos dos territórios costumam desempenhar. No oeste de Santa Catarina, onde as transformações na agroindústria de carne, de forte presença histórica na região, produziram efeitos sociais dramáticos principalmente nas áreas rurais, movimentos sociais e instituições com atuação local ou regional protagonizaram iniciativas de busca de novas possibilidades econômicas, com reconversão produtiva. A agroindústria familiar rural despontou nesse processo, promovida por ações no âmbito, por exemplo, do Fórum de Desenvolvimento Regional Integrado, sediado em Chapecó, e do Movimento dos Trabalhadores Rurais Sem Terra, em São Miguel do Oeste.

Palavras-chave: mudanças na agroindústria de carnes; oeste catarinense; busca de alternativas

\section{Economic changes and possibilities for the territories: observing the recent trajectory of the Western region of Santa Catarina}

\begin{abstract}
As a result of both the decentralization of some public functions and the perception that territorial attributes tend to help production in various sectors, the activities of planning and promoting local or regional development became increasingly accomplished at those very levels. In the western region of Santa Catarina, profound changes in poultry and pork processing, an industry historically rooted in that territory, had dramatic effects in rural areas. Social movements and regional institutions engaged themselves in the search of new economic possibilities, implying production reconversion. Family-based agro-industries were privileged in this process, stimulated by measures undertaken, for instance, at the Fórum de Desenvolvimento Regional Integrado, created in Chapecó, and the Movimento dos Trabalhadores Rurais Sem Terra, in São Miguel do Oeste.
\end{abstract}

Keywords: changes in poultry and pork processing; west of Santa Catarina; search of alternatives

JEL Classification: R11, O13

\footnotetext{
* Professor Titular do Departamento de Economia e Relações Internacionais da Universidade Federal de Santa Catarina. E-mail: hoyedo.lins@ufsc.br
} 


\section{Introdução}

O planejamento e a promoção do desenvolvimento nos espaços com menos vitalidade econômica e oportunidades sociais são atividades historicamente pertencentes às funções básicas do Estado. Essas atribuições mostram-se urgentes, sobretudo, em situações de crise na escala regional ou local, entre outras razões pela ameaça à coesão política e social que as turbulências costumam representar. Circunstâncias dessa natureza crivam a história do capitalismo, ensejando abordagens na literatura internacional ao estilo da produzida por Carney, Hudson e Lewis (1980).

As referidas ações públicas se alteraram nas últimas décadas, tendo a escala regional ou local adquirido proeminência, no planejamento e na promoção do desenvolvimento, em detrimento da esfera nacional. Foi nesse processo que ganhou corpo a ideia de desenvolvimento local, sendo importante observar que "local" diz respeito tanto a lugar como a região, mostrandose relacional em face do Estado nação ou de estados federados (ou províncias, por exemplo), sendo este um aspecto básico no seu reconhecimento. De outra parte, não é raro "local" aparecer associado a "endógeno", como em Vásquez Barquero (2001, p. 57, nota 6): “Quando se fala de desenvolvimento local, está-se fazendo referência a processos de desenvolvimento endógeno [...].”, considerando-se que, “[...] em última análise, são as iniciativas e o controle exercidos pelos atores locais e a sociedade civil, através de suas respostas estratégicas, que contribuem para os processos de transformação de cidades e regiões." (VÁSQUEZ BARQUERO, 2001, p. 10).

A proeminência da dimensão regional/local na promoção do desenvolvimento resultou, certamente entre outros fatores, da convergência de dois importantes processos, que se fortaleceram mutuamente.

Um desses movimentos refere-se à descentralização das atividades do Estado. Desde os anos 1980, vários governos centrais reduziram o seu papel no planejamento do desenvolvimento e no estímulo deste, surgindo ou adquirindo força combinações de iniciativas envolvendo aparatos estatais e coletividades territoriais, de um lado, e setor público e iniciativa privada, de outro. Essa tendência inseriu-se em mudanças mais gerais na atuação do Estado, comparativamente ao que vigorou durante o crescimento econômico após a Segunda Guerra Mundial. Para além do fim dessa expansão econômica, o movimento refletiu a lógica neoliberal impregnada na atmosfera política e ideológica desde os anos 1970 (BOURDIEU, 1998).

Várias funções públicas foram transferidas para menores níveis jurisdicionais, representando descentralização político-administrativa (MOULAERT; SWYNGEDOUW; 
WILSON, 1988). Esta, no Brasil, é prevista na Constituição Federal de 1988, que determinou o deslocamento de importantes atribuições especialmente para os municípios (BRASIL, 1988).

Outra causa da ascensão da esfera regional/local tem a ver com as órbitas da produção e da organização industrial. Desde os anos 1980, diversos pesquisadores se interessaram por experiências produtivas setorialmente especializadas e espacialmente concentradas, em aglomerações povoadas de empresas (geralmente de menor porte) e com instituições vinculadas. O livro de Piore e Sabel (1984) sobre a italiana Emilia Romagna inaugurou caudalosa sequência de estudos sobre o que foi genericamente referido como "estrutura urbana e regional "pósfordista"” (ESSER; HIRSCH, 1989), exibindo ambientes com externalidades favorecidas pela proximidade e por intensas relações face a face, as quais, quando fortemente cooperativas, permitem falar em distritos industriais, redutos de "eficiência coletiva" (SCHMITZ, 1995). A importância da cooperação nesses espaços é indiscutível: a prática facilita a difusão local do conhecimento e impulsiona a inovação, mormente em "regiões de aprendizagem", onde processos de aprendizagem coletiva são institucionalmente apoiados e nutridos (MORGAN, 1997).

Sobressai nessa reflexão a noção de território, que Garofoli (1993, p. 24) diz referir à “[...] aglomeração de relações sociais [...] [e ao] lugar onde a cultura local e outros aspectos locais não transferíveis se sedimentaram.", constituindo, portanto, recursos específicos principalmente em termos de conhecimento. O território representa plano privilegiado do "enraizamento" (ou “imersão”) referido por Granovetter (1985, p. 487), quando este diz que as ações deliberadas dos agentes estão sempre "[...] enraizadas nos existentes sistemas de relações sociais concretas." Constitui também esfera de reconhecimento do habitus, um conceito utilizado por Bourdieu (1997; 2002) que permite consignar que, se os territórios condicionam as ações dos agentes, estes sempre exibem espontaneidade e uma razão prática nas suas condutas, quer dizer, voluntarismo.

A combinação de enraizamento/imersão e voluntarismo permeia o debate sobre desenvolvimento local ligado às aglomerações produtivas. Se alguns lugares se saem melhor do que outros, os atributos dos bem sucedidos, incluindo a mobilização social ostentada, devem ser realçados nas abordagens. Tem destaque o papel dos agentes locais em reconhecer e avaliar os problemas e propor medidas, assim como planejar e executar ações. A atuação do setor público é básica, pois o “[...] local é sempre um 'lugar político' onde o desenvolvimento se realiza graças a 
um [...] grupo social catalisador das potencialidades locais.” (LIPIETZ, 2002), postulação que implica aceitar estarem na esfera política as principais forças promotoras do desenvolvimento.

A problemática do desenvolvimento nesses termos é o assunto geral deste artigo, cujo objetivo é preciso: descrever e analisar aspectos importantes da trajetória socioeconômica do oeste de Santa Catarina nas últimas décadas, realçando mudanças e iniciativas protagonizadas em face das adversidades. "Oeste catarinense" significa uma grande porção ocidental desse estado, caracterizada, em primeiro lugar, pela forte presença da agroindústria de carnes (suínos, aves) articulada à agropecuária de pequeno porte pelo sistema de integração. Mudanças importantes nesse setor afetaram profundamente a região, com a ideia de crise passando a marcar diversos discursos e a inspirar diferentes iniciativas, algumas das quais são mencionadas no artigo.

Na próxima parte caracteriza-se a região, focando aspectos históricos e alguns processos socioeconômicos que se intensificaram nos anos 1990. Em seguida abordam-se iniciativas protagonizadas em escala territorial para enfrentar o que se percebia como um inquietante quadro de adversidades. As considerações finais contêm, basicamente, uma síntese do texto.

\section{Oeste catarinense: mudanças produtivas e tendências desde o final do século $\mathbf{X X}$}

Na regionalização do Instituto Brasileiro de Geografia e Estatística (IBGE), dizer oeste de Santa Catarina significa referir à grande porção ocidental desse estado desde, grosso modo, o vale do Rio do Peixe: trata-se da Mesorregião Oeste Catarinense, formada pelas microrregiões de Chapecó, Concórdia, Joaçaba, São Miguel do Oeste e Xanxerê, com mais de cem municípios e, no Censo Demográfico de 2010, 1.200,7 mil residentes, 19,2\% do total estadual - uma proporção inferior à do Censo de 1991, quando atingiu 23,1\%. Nessa área a participação da população rural supera amplamente a registrada no agregado estadual, destacando-se, sobretudo, a Microrregião de São Miguel do Oeste, mesmo com a retração observada (Tabela 1).

Esse quadro é compatível com a proeminência regional, no plano catarinense, apontada no Censo Agropecuário de 2006 (IBGE, 2009) em relação aos estabelecimentos agropecuários, especialmente dos que registram produção agroindustrial. A Microrregião de Chapecó mostra-se em primeiro lugar a esse respeito, na comparação com as outras microrregiões (Tabela 2). 
Revista Catarinense de Economia - RCE

APEC - Associação dos Pesquisadores em Economia Catarinense

1ํ Semestre de 2017 - www.apec.pro.br/rce

Tabela 1 - Santa Catarina, Mesorregião Oeste e respectivas microrregiões (MR) e municípios principais: população total e rural nos censos demográficos de 1991, 2000 e 2010 (mil residentes)

\begin{tabular}{|c|c|c|c|c|c|c|c|c|c|}
\hline \multirow{3}{*}{$\begin{array}{l}\text { Anos/População } \\
\text { Área }\end{array}$} & \multicolumn{3}{|c|}{1991} & \multicolumn{3}{|c|}{2000} & \multicolumn{3}{|c|}{2010} \\
\hline & \multirow{2}{*}{$\begin{array}{c}\text { Popul. } \\
\text { total }\end{array}$} & \multicolumn{2}{|c|}{ Popul. rural } & \multirow{2}{*}{$\begin{array}{c}\text { Popul. } \\
\text { total }\end{array}$} & \multicolumn{2}{|c|}{ Popul. rural } & \multirow{2}{*}{$\begin{array}{c}\text { Popul. } \\
\text { total }\end{array}$} & \multicolumn{2}{|c|}{ Popul. rural } \\
\hline & & $\mathrm{N}^{\mathrm{o}}$ & $\%$ & & $\mathrm{~N}^{\mathrm{o}}$ & $\%$ & & $\mathrm{~N}^{\mathrm{o}}$ & $\%$ \\
\hline Santa Catarina & $4.542,0$ & $1.333,5$ & 29,3 & $5.356,4$ & $1.138,4$ & 21,2 & $6.248,4$ & $1.000,5$ & 16,0 \\
\hline Mesorreg. Oeste & $1.051,1$ & 518,1 & 49,3 & $1.116,8$ & 414,1 & 37,1 & $1.200,7$ & 340,1 & 28,3 \\
\hline MR Chapecó & 340,5 & 168,3 & 49,4 & 361,1 & 128,3 & 35,5 & 405,1 & 106,1 & 26,2 \\
\hline Mun. Chapecó & 123,0 & 26,3 & 21,4 & 147,0 & 12,4 & 8,4 & 183,5 & 15,4 & 8,4 \\
\hline MR Concórdia & 130,6 & 73,6 & 56,4 & 137,9 & 60,3 & 43,7 & 142,0 & $\overline{48,6}$ & 34,2 \\
\hline Mun. Concórdia & 63,3 & 28,1 & 44,5 & 63,1 & 17,8 & 28,2 & 68,6 & 13,8 & 20,1 \\
\hline MR Joaçaba & 262,9 & 91,3 & 34,7 & 304,0 & 79,7 & 26,2 & 326,5 & 63,7 & 19,5 \\
\hline Mun. Joaçaba & 28,1 & 4,9 & 17,4 & 24,1 & 2,4 & 10,0 & 27,0 & 2,1 & 7,8 \\
\hline MR S. M. Oeste & 186,8 & 120,4 & 64,4 & 171,2 & 89,4 & 52,2 & 174,7 & 73,5 & 42,1 \\
\hline Mun. S. M. Oeste & 42,2 & 16,6 & 39,3 & 32,3 & 4,9 & 15,2 & 36,3 & 4,2 & 11,6 \\
\hline MR X: & 130,3 & 64,5 & 49,5 & 142,3 & $\overline{56,4}$ & 39,6 & 152,5 & 48,2 & 31,6 \\
\hline Mun. Xanxerê & 37,6 & 9,9 & 26,3 & 37,4 & 5,0 & 13,4 & 44,1 & 5,0 & 11,3 \\
\hline
\end{tabular}

Fonte: elaborado pelo autor com dados de IBGE (1991; 2000; 2010)

Tabela 2 - Santa Catarina, Mesorregião Oeste e respectivas microrregiões (MR): número de estabelecimentos agropecuários com produção por tipo de estabelecimento e produção (2006)

\begin{tabular}{l|r|r|r|r|r|r|r|r}
\hline \multirow{2}{*}{ Estab./Produção } & \multicolumn{3}{|c|}{ Total de estabelecimentos } & \multicolumn{3}{c}{ Estabelecimentos de agricultura familiar } \\
\cline { 2 - 9 } Área & $\begin{array}{c}\text { Produção } \\
\text { total }\end{array}$ & $\%$ & $\begin{array}{c}\text { Prod. } \\
\text { agroindust. }\end{array}$ & $\%$ & $\begin{array}{c}\text { Produção } \\
\text { total }\end{array}$ & $\%$ & $\begin{array}{c}\text { Prod. } \\
\text { agroindust. }\end{array}$ & $\%$ \\
\hline Santa Catarina & 178.430 & 100 & 4.667 & 100 & 155.908 & 100 & 4.144 & 100 \\
\hline Mesorreg. Oeste & 78.505 & 44,0 & 3.303 & 70,8 & 70.377 & 45,1 & 3.011 & 72,7 \\
\hline MR Chapecó & 26.598 & 14,9 & 1.461 & 31,3 & 24.238 & 15,5 & 1.345 & 32,4 \\
\hline MR Concórdia & 11.637 & 6,5 & 569 & 12,2 & 10.550 & 6,8 & 511 & 12,3 \\
\hline MR Joaçaba & 12.074 & 6,8 & 385 & 8,2 & 10.176 & 6,5 & 319 & 7,7 \\
\hline MR S. M. Oeste & 18.466 & 10,3 & 627 & 13,4 & 17.099 & 11,0 & 593 & 14,3 \\
\hline MR Xanxerê & 9.730 & 5,4 & 261 & 5,6 & 8.314 & 5,3 & 243 & 5,9 \\
\hline
\end{tabular}

Fonte: elaborado pelo autor com dados do Censo Agropecuário de 2006 (IBGE, 2009), por meio do Sistema IBGE de Recuperação Automática (SIDRA). https://sidra.ibge.gov.br/tabela/1118

A Microrregião de Chapecó é a mais populosa, uma condição ostentada igualmente, e de longe, por seu município sede, cuja área urbana tinha um alto nível de centralidade regional no final do século passado (CARACTERIZAÇÃO..., 2000) e reunia condições de capital regional ao final dos anos 2000 (IBGE, 2008). A expansão demográfica de Chapecó, cuja população total cresceu 49\% entre os censos de 1991 e 2010, reflete as transformações produtivas das últimas décadas no oeste catarinense, como assinalam, entre outros, Fujita, Maia e Alba (2013). São essas mudanças que figuram na base da percepção, incrustada no tecido social e político regional pelo menos na década de 1990, de que a região vivenciava inquietante quadro de crise: pesquisa 
realizada em 1999 junto a dezenas de agentes em treze municípios (nos setores público e privado) constatou ser disseminado o entendimento de que a situação era grave (THEIS; NODARI, 2000).

Subjacentes aos problemas perfilavam-se alterações significativas no sistema produtor de carnes (suínos e de aves), de presença histórica naquelas latitudes do estado, como se falou. Essa incidência tem caráter histórico porque é indissociável dos processos iniciados com a efetiva ocupação do oeste, no começo do século XX, mais especificamente desde 1916, após a Guerra do Contestado e a assinatura do Acordo de Limites que pôs fim à disputa entre Santa Catarina e Paraná pelas terras daquela região.

Até então, o oeste era visto como um imenso vazio, não obstante a presença (antiga) de muitos indígenas, a ponto de, numa expedição realizada por volta de 1814 , ter-se observado que o oeste “[...] era infestado de silvícolas que ocupavam o território [...].” (CABRAL, 1968, p. 313). Além dos índios, havia apenas a presença esparsa, desde o século XIX, de caboclos interessados na extração de madeira e erva-mate, na criação de gado ou em cultivos para subsistência, vindos não só de províncias próximas, mas até da Argentina, segundo Silva e Rosa (2010).

Finda a Guerra do Contestado, desencadeou-se movimento em harmonia com o intuito institucional de "povoar" a região, sob o estímulo dos desdobramentos da viagem do governador de Santa Catarina (Adolfo Konder) ao oeste entre abril e maio de 1929 (cf., p. ex., Flores e Serpa, 1999). O início envolveu, de um lado, o assentamento em glebas de pequeno porte, por empresas colonizadoras, de numerosas famílias de agricultores descendentes de europeus (italianos, alemães) vindas do noroeste do Rio Grande do Sul, numa frente de crescimento daquela área colonial no estado vizinho (GOULARTI FILHO, 2002; PAIM, 2006; SILVA; ROSA, 2010). De outro lado, como assinala Rossetto (1986), a dinâmica escorou-se na concessão pelo governo catarinense de enormes superfícies de terra a empresários da colonização, que também adquiriram títulos e direitos de herdeiros de fazendeiros paranaenses e paulistas.

Nas propriedades rurais assim surgidas, a suinocultura enraizou-se desde logo como importante atividade econômica, com sistema produtivo de policultura subordinada àquela prática e estruturada dentro da pequena propriedade familiar (TESTA et al., 1996). Os resultados comerciais, ligados a crescimento na demanda por alimentos (em diferentes escalas) que permitia um atraente escoamento da produção, fizeram o suíno ocupar o centro da reprodução das unidades familiares, repercutindo na sua organização e divisão do trabalho (FERRARI, 2003). 
Nos anos 1950, em experiência de empresa agroindustrial que se tornaria líder no Brasil (Sadia), surgiu no oeste o modelo de integração entre atividades de abate e processamento e produtores rurais. Esse modelo fixou-se e se disseminou, e, a partir de então, ganhou vigor, notadamente na década de 1980. Sua base é o compromisso contratual em torno da criação dos animais nas propriedades, conforme as determinações das empresas de carne, que os absorvem dos produtores no momento do abate. Os suinocultores praticaram por anos o chamado ciclo completo, implicando amplo controle sobre o processo, com produção de vários insumos na esfera da propriedade (o que permite menores custos e maiores ganhos) e compra de medicamentos e outros itens, pagos às empresas quando da entrega dos animais.

Espíndola (1996) afirma que, após a década de 1970, essa trajetória provocou importantes transformações em unidades familiares, envolvendo introdução de sistemas computadorizados e trabalho assalariado, junto com a melhoria e a expansão dos rebanhos. Para isso concorreram recursos públicos voltados à maior tecnificação da produção (envolvendo importações de máquinas e equipamentos e aprimoramento genético), almejando-se avançar em produtividade e competitividade (WEYDMANN et al., 2008).

Nesse processo, um verdadeiro cluster suinícola ganhou contornos no oeste, exibindo instituições com atuação em ensino e pesquisa, coordenação e representação de interesses, assim como diversas atividades de apoio, além das empresas e propriedades rurais (SANTOS FILHO et. al., 1999). O papel das maiores agroindústrias (Sadia e Perdigão, que se fundiram em 2009, surgindo a Brasil Foods, ou BRF, e também Aurora e Seara, esta comprada pela Marfrig em 2009) foi determinante: protagonizaram até "gestão territorial", traduzida, por exemplo, na repartição do espaço conforme a localização das propriedades rurais integradas (OESTE..., 2010).

O setor avícola emergiu com força a partir dos anos 1960, quando empresas que industrializavam carne suína decidiram diversificar suas atividades, um processo que atingiria a carne bovina nos anos 1980 (CARVALHO JÚNIOR.; CARIO; SEABRA, 2009). Nesse movimento usufruíram, mormente a partir da década de 1970, de recursos públicos para modernização agroindustrial no país, sob o estímulo dos resultados das exportações (BELUSSO; HESPANHOL, 2010).

Diferentemente da suinocultura, a avicultura moderna, isto é, aquela realizada nas propriedades para suprir o beneficiamento de carne (principalmente) de frango, já surgiu sob o signo da integração. Portanto, desde o início as empresas industriais controlaram todo o processo 
produtivo, atuando igualmente, além do processamento industrial, em criação de matrizes, fornecimento de aves recém nascidas às propriedades rurais, produção de ração, assistência técnica e transporte, cabendo aos produtores a engorda conforme as determinações das primeiras (LAZZARI, 2004).

Não demorou muito para que uma atividade inicialmente pouco representativa ganhasse forte relevância e se tornasse parte essencial de um dos setores mais importantes do estado, com notável desempenho exportador (ALVES; WEYDMANN, 2008). Investimentos em tecnologias de várias áreas do conhecimento (química, mecânica/automação, biotecnologia, informática) estiveram por trás da trajetória registrada. Isso repercutiu em aspectos como genética, nutrição e sanidade, e, na esfera do processamento/beneficiamento, até no aumento da oferta de itens com maior valor agregado, como pratos prontos ou semiprontos, em sintonia com mudanças mais gerais no setor agroalimentar (WILKINSON, 2002).

A dimensão dos rebanhos de suínos e aves no oeste catarinense é sugestiva da importância adquirida pela agroindústria de carne na região. A tabela 3 é eloquente a respeito, permitindo observar a participação de Santa Catarina e da Mesorregião Oeste nos totais nacionais com dados, grosso modo, para os últimos vinte e cinco anos.

Tabela 3 - Brasil, Santa Catarina e Mesorregião Oeste: efetivos dos rebanhos suíno e de aves (número de cabeças): 1990-2015

\begin{tabular}{|c|c|c|c|c|c|c|}
\hline & \multicolumn{2}{|c|}{ Brasil } & \multicolumn{2}{|c|}{ Santa Catarina } & \multicolumn{2}{|c|}{ Mesorregião Oeste } \\
\hline & $\mathrm{N}^{\mathrm{o}}$ & $\%$ & $\mathrm{~N}^{\circ}$ & $\%$ & $\mathrm{~N}^{\circ}$ & $\%$ \\
\hline \multicolumn{7}{|c|}{ Suínos } \\
\hline 1990 & 33.623 .186 & 100 & 3.330 .516 & 9,9 & 2.217 .430 & 6,6 \\
\hline 1995 & 36.062 .103 & 100 & 4.404 .480 & 12,2 & 3.056 .931 & 8,5 \\
\hline 2000 & 31.562 .111 & 100 & 5.093 .888 & 16,1 & 3.788 .836 & 12,0 \\
\hline 2005 & 34.063 .934 & 100 & 6.309 .041 & 18,5 & 4.868 .346 & 14,3 \\
\hline 2010 & 38.956 .758 & 100 & 7.817 .536 & 20,1 & 5.945 .042 & 15,3 \\
\hline 2015 & 40.332 .553 & 100 & 6.792 .724 & 16,9 & 4.543 .099 & 11,3 \\
\hline \multicolumn{7}{|c|}{ Aves } \\
\hline 1990 & 546.235 .505 & 100 & 66.636 .309 & 12,2 & 51.401 .700 & 9,4 \\
\hline 1995 & 729.531 .299 & 100 & 84.146 .740 & 11,5 & 61.534 .354 & 8,4 \\
\hline 2000 & 842.740 .173 & 100 & 123.740 .489 & 14,7 & 90.770 .113 & 10,8 \\
\hline 2005 & 999.041 .234 & 100 & 156.339 .440 & 15,6 & 114.428 .936 & 11,4 \\
\hline 2010 & 1.238 .912 .537 & 100 & 173.767 .575 & 14,0 & 117.961 .302 & 9,5 \\
\hline 2015 & 1.332 .078 .050 & 100 & 145.153 .142 & 10,9 & 103.095 .353 & 7,7 \\
\hline
\end{tabular}

Fonte: elaborado pelo autor com dados de IBGE - Sistema IBGE de Recuperação Automática (SIDRA) https://sidra.ibge.gov.br/tabela/3939\#resultado 
$\mathrm{Na}$ tabela 4 o recorte adotado é microrregional, apontando o número tanto de estabelecimentos com suinocultura e avicultura como de cabeças, para a totalidade dos estabelecimentos e para os de agricultura familiar. A presença é maior nas microrregiões de Chapecó, Concórdia, Joaçaba e São Miguel do Oeste, variando conforme se considerem estabelecimentos ou cabeças.

Tabela 4 - Santa Catarina, Mesorregião Oeste e respectivas microrregiões (MR): número de estabelecimentos agropecuários com suínos e aves, total e com agricultura familiar (2006)

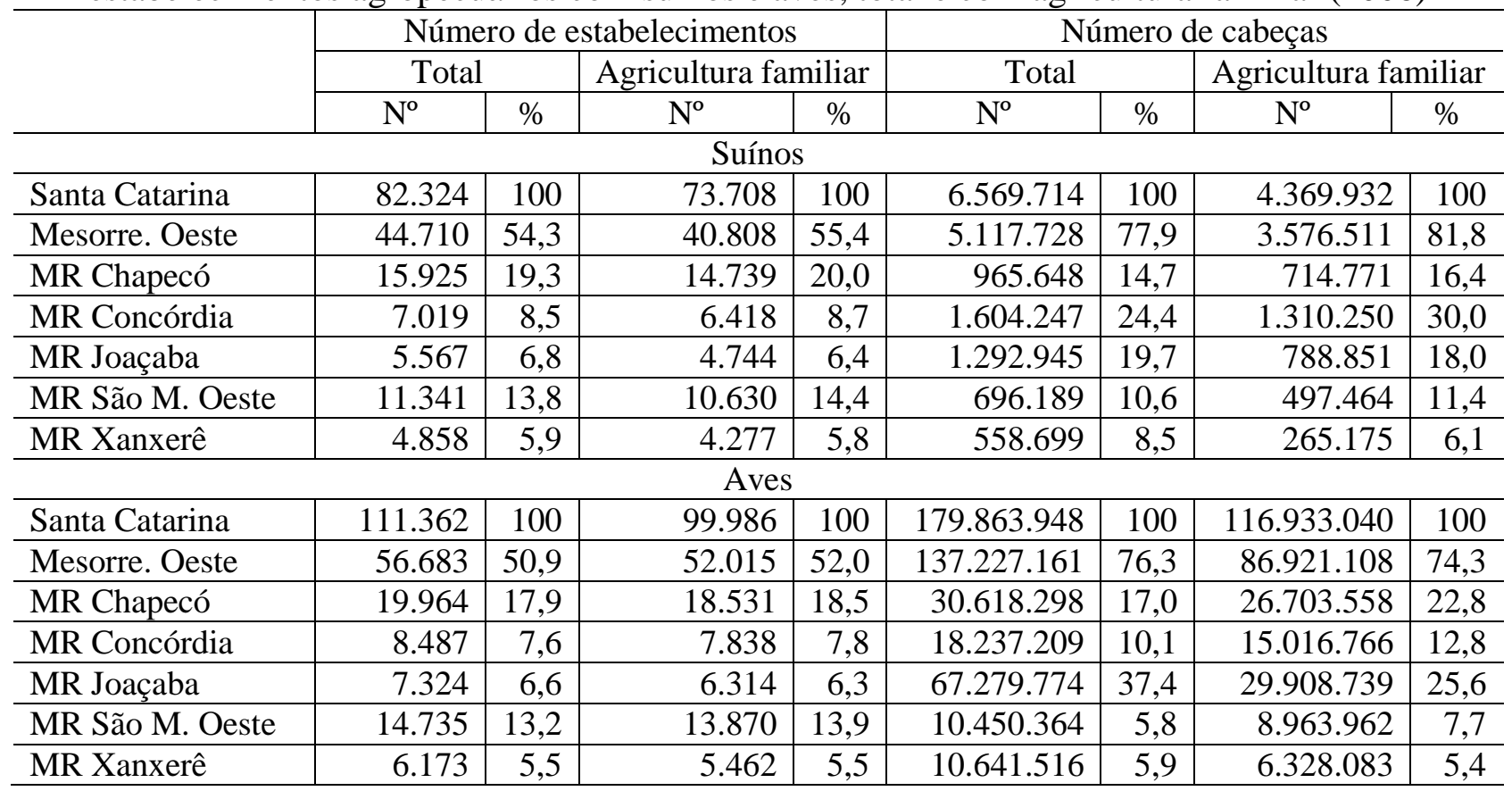

Fonte: elaborado pelo autor com dados do Censo Agropecuário de 2006 (IBGE, 2009), por meio do Sistema IBGE de Recuperação Automática (SIDRA). Para suínos: https://sidra.ibge.gov.br/tabela/1225; para aves: https://sidra.ibge.gov.br/tabela/1226 Acesso em 12 jan. 2017

Todavia, conforme realçado por Buainan (2007), esse processo de modernização agroindustrial revelou-se seletivo e excludente. À medida que as empresas de abate e processamento avançavam em tecnologia e presença no mercado, notadamente de exportação com as vinculadas imposições, como assinala Espíndola (2002) -, cresciam as exigências para as propriedades rurais implicadas, compelidas a investir no aprimoramento de suas atividades, alterando a base técnica/tecnológica e aumentando a intensidade de capital. A produção de suínos, por exemplo, experimentou diversos estágios em percurso alinhado, conforme Coletti e Lins (2011, p. 348), com “[...] as necessidades em termos de instalações e equipamentos, de 
relações com o mercado e com as empresas agroindustriais e também de quantidade produzida para fins comerciais."

O ponto central é que os obstáculos enfrentados por numerosos produtores redundaram em desligamento de muitas propriedades das estruturas de integração. Um importante resultado foi a intensificação do processo de concentração, seja na suinocultura ou na avicultura (PLEIN, 2006). Essa dinâmica nutriu migrações refletidas na supressão de 178 mil residentes do meio rural da Mesorregião Oeste Catarinense - um recuo de 34\% - e no crescimento de algumas cidades daquele território, Chapecó à frente, entre os censos demográficos de 1991 e 2010 (cf. a Tabela 1, já apresentada).

Foram essas as principais transformações na base produtiva regional que, contribuindo decisivamente para o abandono de áreas e para o esvaziamento em diversos municípios, ajudaram a inocular a assinalada ideia de que o oeste catarinense vivenciava grave crise em meados dos anos 1990. Mas também compunha o quadro o percebido comprometimento de mananciais de água em vários locais, uma consequência, segundo Silva e Bassi (2012), do aumento na escala e na concentração da produção. Muito acima dos limites aceitos internacionalmente, o nível de contaminação se relacionava a problemas de estocagem dos dejetos nas esterqueiras, entre outros fatores (ASSIS; MURATORI, 2007). De um modo geral, esse manejo era prática que exigia melhorias, sob pena de ameaçar a própria sustentabilidade daquele sistema de produção de carnes (SANTOS FILHO et al., 1999; TESTA et al., 1996).

Investimentos realizados pelas principais empresas agroindustriais em outras regiões do Brasil, como captado por Helfand e Rezende (1999), também preocupavam. Não sem exagero, chegou-se a imaginar um processo de desindustrialização regional, pois novas capacidades de abate e processamento eram criadas no Centro Oeste e no Nordeste do país: a Perdigão, por exemplo, instalou um grande complexo no sudoeste de Goiás no final dos anos 1990 (LINS; GOULART, 2013), e a Sadia projetou-se em outras localizações, como no Mato Grosso e em Pernambuco. A combinação de atributos territoriais e incentivos fiscais foi determinante nessa reconfiguração, embora no Centro Oeste tenha pesado a grande presença do cultivo de grãos (soja, milho), básicos na produção de ração e nos custos da suinocultura e avicultura.

Mas as empresas investiram também no oeste catarinense, e a estrutura industrial da região foi preservada, a julgar pelos dados sobre empregos formais entre 1995 e 2015. A rigor, tal estrutura ganhou em diversificação, pois ao menos dois outros setores exibiram forte 
crescimento, o lácteo e o moveleiro, devendo-se ressaltar que as informações a esse respeito aqui utilizadas limitam-se ao plano formal. Assim, para atividades nas quais a informalidade é alta, com predominância, por exemplo, de mão de obra familiar - como em vários itens da chamada produção colonial (queijos, salames, geleias) - , os dados indicariam somente o "piso" da situação correspondente.

A tabela 5 mostra o movimento expansivo (embora oscilante) do emprego formal no abate de aves e animais pequenos e na preparação de produtos de carnes. A participação do oeste como um todo no estado permanece muito alta, mesmo recuando entre 1995 e 2015. A Microrregião de Chapecó exibe o maior destaque quanto ao crescimento, e as de Concórdia e Joaçaba sobressaem no sentido contrário.

Tabela 5 - Santa Catarina, Mesorregião Oeste Catarinense e respectivas microrregiões (MR): empregados formais no abate de aves e de outros pequenos animais e na preparação de produtos

\begin{tabular}{|c|c|c|c|c|c|c|c|c|c|c|}
\hline & \multicolumn{2}{|c|}{1995} & \multicolumn{2}{|c|}{2000} & \multicolumn{2}{|c|}{2005} & \multicolumn{2}{|c|}{2010} & \multicolumn{2}{|c|}{2015} \\
\hline & $\mathrm{N}^{\mathrm{o}}$ & $\%$ & $\mathrm{~N}^{\mathrm{o}}$ & $\%$ & $\mathrm{~N}^{\mathrm{o}}$ & $\%$ & $\mathrm{~N}^{\mathrm{o}}$ & $\%$ & $\mathrm{~N}^{\mathrm{o}}$ & $\%$ \\
\hline Santa Catarina & 16.837 & 100 & 17.131 & 100 & 30.006 & 100 & 25.610 & 100 & 25.644 & 100 \\
\hline Mesorregião Oeste & 13.844 & 82,2 & 15.313 & 89,4 & 24.883 & 82,9 & 17.010 & 66,4 & 19.708 & 76,8 \\
\hline MR Chapecó & 6.983 & 41,5 & 5.449 & 31,8 & 9.396 & 31,3 & 8.696 & 34,0 & 9.816 & 38,3 \\
\hline MR Concórdia & 4.619 & 27,4 & 4.877 & 28,5 & 7.364 & 24,5 & 2.425 & 9,5 & 2.759 & 10,8 \\
\hline MR Joaçaba & 29 & 0,2 & 3.390 & 19,8 & 5.406 & 18,0 & 0 & 0 & 357 & 1,4 \\
\hline MR São M. do Oeste & 4 & 0,02 & 1 & . & 2.705 & 9,0 & 3.215 & 12,5 & 2.587 & 10,1 \\
\hline MR Xanxerê & 2.209 & 13,1 & 1.596 & 9,3 & 12 & 0,04 & 2.674 & 10,4 & 4.189 & 16,3 \\
\hline
\end{tabular}

Fonte: elaborado pelo autor com dados da Relação Anual de Informações Sociais (RAIS) <http://bi.mte.gov.br/bgcaged/rais.php>

Obs.: os dados correspondem ao código 15121 da CNAE 95 Classe

A tabela 6, sobre preparação de carne, banha e salsicharia não vinculada ao abate, representa contraponto à tendência anterior, pois exibe um declínio acentuado geral dos empregados formais desde meados dos anos 2000. Como a representatividade do oeste no estado é alta, a retração se reflete nos números absolutos. Conforme se verá posteriormente, é expressiva a participação de estabelecimentos de menor porte nessas atividades, sugerindo que problemas enfrentados por empresas menores podem estar por trás da tendência de queda. 
Tabela 6 - Santa Catarina, Mesorregião Oeste Catarinense e respectivas microrregiões (MR): empregados formais na preparação de carne, banha e produtos de salsicharia não associada ao abate $-1995-2015$

\begin{tabular}{|c|c|c|c|c|c|c|c|c|c|c|}
\hline & \multicolumn{2}{|c|}{1995} & \multicolumn{2}{|c|}{2000} & \multicolumn{2}{|c|}{2005} & \multicolumn{2}{|c|}{2010} & \multicolumn{2}{|c|}{2015} \\
\hline & $\mathrm{N}^{\mathrm{o}}$ & $\%$ & $\mathrm{~N}^{\circ}$ & $\%$ & $\mathrm{~N}^{\circ}$ & $\%$ & $\mathrm{~N}^{\circ}$ & $\%$ & $\mathrm{~N}^{\circ}$ & $\%$ \\
\hline Santa Catarina & 2.698 & 100 & 2.288 & 100 & 2.758 & 100 & 604 & 100 & 756 & 100 \\
\hline Mesorregião Oeste & 1.160 & 43,0 & 1.548 & 67,7 & 1.376 & 49,9 & 217 & 35,9 & 308 & 40,7 \\
\hline $\mathrm{MR} \mathrm{Cl}$ & 1.072 & 39,7 & 1.055 & 46,1 & 807 & 29,3 & 42 & 6,9 & 20 & 2,6 \\
\hline MR Concórdia & 0 & 0 & 3 & 0,1 & 38 & 1,4 & 38 & 6,3 & 9 & 1,2 \\
\hline MR Joaçaba & 16 & 0,6 & 490 & 21,4 & 472 & 17,1 & 1 & 0,2 & 80 & 10,6 \\
\hline MR São M. do Oeste & 68 & 2,5 & 0 & 0 & 7 & 0,2 & 0 & 0 & 0 & 0 \\
\hline MR Xanxerê & 4 & 0,1 & 0 & 0 & 52 & 1,9 & 136 & 22,5 & 199 & 26,3 \\
\hline
\end{tabular}

Fonte: elaborado pelo autor com dados da Relação Anual de Informações Sociais (RAIS) <http://bi.mte.gov.br/bgcaged/rais.php>

Obs.: os dados correspondem ao código 15130 da CNAE 95 Classe

A tabela 7 informa sobre a fabricação de produtos do laticínio, de vertiginosa ascensão no oeste (sobretudo nas microrregiões de Chapecó e Joaçaba), ganhando o setor lácteo crescente destaque como alternativa perante o quadro de crise, marcado pela exclusão de muitos produtores dos vínculos com as agroindústrias. A produção acenava positivamente em quase todas as propriedades rurais, pois já existia em muitas, mesmo que em pequena escala ou para consumo familiar, e representaria um ingresso regular de receita (TESTA et al., 2003). Esse setor sobressaiu, assim, na reconversão de muitos produtores rurais do oeste catarinense.

Tabela 7 - Santa Catarina, Mesorregião Oeste Catarinense e respectivas microrregiões (MR): empregados formais na fabricação de produtos do laticínio - 1995-2015

\begin{tabular}{|c|c|c|c|c|c|c|c|c|c|c|}
\hline & \multicolumn{2}{|c|}{1995} & \multicolumn{2}{|c|}{2000} & \multicolumn{2}{|c|}{2005} & \multicolumn{2}{|c|}{2010} & \multicolumn{2}{|c|}{2015} \\
\hline & $\mathrm{N}^{\circ}$ & $\%$ & $\mathrm{~N}^{\mathrm{o}}$ & $\%$ & $\mathrm{~N}^{\mathrm{o}}$ & $\%$ & $\mathrm{~N}^{\mathrm{o}}$ & $\%$ & $\mathrm{~N}^{\mathrm{o}}$ & $\%$ \\
\hline Santa Catarina & 1.634 & 100 & 1.502 & 100 & 2.360 & 100 & 3.764 & 100 & 4.907 & 100 \\
\hline Mesorregião Oeste & 467 & 28,6 & 564 & 37,5 & 1.191 & 50,5 & 2.536 & 67,4 & 3.607 & 73,5 \\
\hline MR Chapecó & 145 & 8,9 & 115 & 7,7 & 178 & 7,5 & 841 & 22,3 & 1.115 & 22,7 \\
\hline MR Concórdia & 35 & 2,1 & 61 & 4,1 & 75 & 3,2 & 316 & 8,4 & 244 & 5,0 \\
\hline MR Joaçaba & 148 & 9,1 & 195 & 13,0 & 397 & 16,8 & 603 & 16,0 & 1.110 & 22,6 \\
\hline do Oest & 113 & 6,9 & 159 & 10,6 & 403 & 17,1 & 514 & 13,7 & 815 & 16,6 \\
\hline MR Xanxerê & 26 & 1,6 & 34 & 2,3 & 138 & 5,8 & 262 & 7,0 & 323 & 6,6 \\
\hline
\end{tabular}

Fonte: elaborado pelo autor com dados da Relação Anual de Informações Sociais (RAIS) <http://bi.mte.gov.br/bgcaged/rais.php $>$

Obs.: os dados correspondem ao código 15423 da CNAE 95 Classe

É sugestivo da trajetória regional do setor lácteo que o oeste produzisse, na ocasião do Censo Agropecuário de 2006 (IBGE, 2009), pouco menos de 3/4 do leite catarinense. A 
Revista Catarinense de Economia - RCE

APEC - Associação dos Pesquisadores em Economia Catarinense

1ํ Semestre de 2017 - www.apec.pro.br/rce

Microrregião de Chapecó detinha o maior destaque, seguida pela de São Miguel do Oeste (Tabela $8)$.

Tabela 8 - Santa Catarina, Mesorregião Oeste Catarinense e respectivas microrregiões (MR): volume de leite produzido (litros) - 2006

\begin{tabular}{l|rr|rr}
\hline & \multicolumn{2}{|c|}{ Total de estabelecimentos } & \multicolumn{2}{c}{ Estabelec. de agricultura familiar } \\
\cline { 2 - 5 } & Litros de leite & \multicolumn{1}{c}{$\%$} & \multicolumn{1}{c}{ Litros de leite } & \multicolumn{1}{c}{ \% } \\
\hline Santa Catarina & 1.396 .797 .005 & 100 & 1.215 .389 .903 & 100 \\
\hline Mesorregião Oeste & 1.022 .861 .386 & 73,2 & 909.189 .096 & 74,8 \\
MR Chapecó & 338.795 .793 & 24,2 & 302.709 .892 & 24,9 \\
MR Concórdia & 172.694 .859 & 12,4 & 157.566 .307 & 13,0 \\
MR Joaçaba & 114.453 .704 & 8,2 & 97.568 .782 & 8,0 \\
MR São M. do Oeste & 290.281 .970 & 20,8 & 268.099 .161 & 22,1 \\
MR Xanxerê & 106.635 .060 & 7,6 & 83.244 .954 & 6,8 \\
\hline
\end{tabular}

Fonte: elaborado pelo autor com dados do Censo Agropecuário de 2006 (IBGE, 2009), por meio do Sistema IBGE de Recuperação Automática (SIDRA). https://sidra.ibge.gov.br/tabela/1227\#resultado

Por último, a tabela 9 sugere uma "explosão" da produção moveleira nas microrregiões de Chapecó, São Miguel do Oeste e Joaçaba. Nas duas primeiras, a presença é dispersa em vários municípios, e na segunda, mais concentrada em Caçador. Atividade de inscrição espacial geralmente urbana, pode-se dizer que seu crescimento reflete, ao menos em parte, a própria expansão das cidades do oeste, representando importante movimento de diversificação produtiva.

Tabela 9 - Santa Catarina, Mesorregião Oeste Catarinense e respectivas microrregiões (MR): empregados formais na fabricação de móveis (madeira, metal e outros materiais) - 1995-2015

\begin{tabular}{|c|c|c|c|c|c|c|c|c|c|c|}
\hline & \multicolumn{2}{|c|}{1995} & \multicolumn{2}{|c|}{2000} & \multicolumn{2}{|c|}{2005} & \multicolumn{2}{|c|}{2010} & \multicolumn{2}{|c|}{2015} \\
\hline & $\mathrm{N}^{\mathrm{o}}$ & $\%$ & $\mathrm{~N}^{\mathrm{o}}$ & $\%$ & $\mathrm{~N}^{\mathrm{o}}$ & $\%$ & $\mathrm{~N}^{\mathrm{o}}$ & $\%$ & $\mathrm{~N}^{\mathrm{o}}$ & $\%$ \\
\hline Santa Catarina & 17.449 & 100 & 25.842 & 100 & 30.215 & 100 & 26.112 & 100 & 27.759 & 100 \\
\hline Mesor. Oeste & 2.262 & 13,0 & 6.395 & 24,7 & 6.858 & 22,7 & 7.374 & 28,2 & 8.296 & 29,9 \\
\hline MR Chapecó & 971 & 5,6 & 2.661 & 10,3 & 2.651 & 8, & 3.401 & 13,0 & 3.560 & 12,8 \\
\hline MR Concórdia & 131 & 0,7 & 164 & 0,6 & 248 & 0,8 & 289 & 1,1 & 532 & 1,9 \\
\hline MR & 700 & 4,0 & 2.244 & 8,7 & 2.378 & 7,9 & 1.383 & 5,3 & 1.406 & 5,1 \\
\hline MR S. M. Oeste & 337 & 1,9 & 1.018 & 3,9 & 1.370 & 4,5 & 2.108 & 8,1 & 2.563 & 9,2 \\
\hline MR Xanxerê & 123 & 0,7 & 308 & 1,2 & 211 & 7,0 & 193 & 0,7 & 235 & 0,8 \\
\hline
\end{tabular}

Fonte: elaborado pelo autor com dados da Relação Anual de Informações Sociais (RAIS)

<http://bi.mte.gov.br/bgcaged/rais.php >

Obs.: os dados correspondem aos códigos 36110, 36129 e 36137 da CNAE 95 Classe 


\section{Em busca do desenvolvimento: iniciativas locais no oeste catarinense}

Assimilada à ideia de crise regional, a conjuntura adversa para muitas famílias de produtores rurais repercutiu junto aos movimentos sociais, dos quais o oeste se tornou um verdadeiro "celeiro" no dizer de Paim (2006). Movimento dos Trabalhadores Rurais Sem Terra, Movimento de Mulheres Agricultoras, Movimento dos Atingidos por Barragens, Associação dos Pequenos Agricultores do Oeste Catarinense são algumas expressões de iniciativas nesse plano, em geral em harmonia (ou mais do que isso) com segmentos da Igreja Católica.

Tentativas de resistência à crise foram colocadas em prática, em geral em condutas típicas da, por assim dizer, "cultura rural" ou "ruralidade": presença de solidariedade e reciprocidade expressas, por exemplo, em mutirões e outras práticas coletivas que eram comuns entre os colonizadores. Ajudou a manter ou fortalecer a tradição associativa a própria religiosidade de grande parte dos contingentes que povoaram a região, manifestada historicamente na assiduidade aos cultos e às atividades sociais promovidas pelas igrejas ou capelas dos municípios. Isso oportunizou encontros e trocas de experiências, quer dizer, convivência capaz de ajudar no equacionamento (coletivo) de problemas (POLI, 2002). A referida tradição configuraria um aspecto desse território, talvez da sua identidade, permeando modo de vida disseminado naquelas latitudes catarinenses.

O papel das relações comunitárias assim galvanizadas parece ter sido essencial na mobilização e na resistência frente aos problemas, nutrindo experiências de busca por alternativas nas quais despontou o associativismo ou o cooperativismo. Mas é importante também assinalar que essa busca de novas possibilidades ganha luz quando se lhe associa o papel dos serviços de extensão rural, que desde os anos 1980 incutiam junto a agricultores do oeste catarinense a ideia de que as ações coletivas eram essenciais, devendo, assim, ser objeto de interesse. Exemplos de resultados foram os "condomínios" de suinocultura, onde os associados realizavam em grupo as etapas de fecundação e recria e atuavam individualmente na finalização do processo, com ganhos de produtividade.

\subsection{Pistas sobre movimentos importantes em alguns setores de atividades}

Iniciativas conjuntas do tipo assinalado, com alcances e desenhos variados, marcaram presença na maioria dos municípios da região, segundo Schmidt et al. (2002). Revelaram-se influentes os atributos territoriais ligados ao "ruralismo" caracterizado por pequenas propriedades 
e predomínio do trabalho familiar, com inclinação para iniciativas compartilhadas. Esse é o quadro em que se deve situar a tendência de agroindustrialização da produção primária, no âmbito familiar, por contingentes que insistiram na busca de alternativas localmente, em vez de emigrar.

Avançar em pluriatividade e em agregação de valor na esfera das pequenas propriedades tornou-se eixo dessa reconversão econômica. Sintoma claro foi o crescimento de atividades envolvendo queijarias, abatedouros e panificadoras, entre muitas outras que recobrem itens como conservas, doces, biscoitos, açúcar mascavo e sucos, empregando mão de obra principalmente familiar e processando produtos próprios ou de vizinhos. Esse movimento contou, sobretudo para a formalização das correspondentes práticas, com o suporte de instituições como a mencionada Associação dos Pequenos Agricultores do Oeste Catarinense (MIOR, 2005; KUNZLER; BADALOTTI, 2014).

Essa "produção colonial", cuja expansão desde os anos 1990 implicou notadamente estabelecimentos rurais marcados pela exclusão dos vínculos com as grandes agroindústrias, caracteriza-se pela orientação ao mercado informal (feiras livres, pequenos armazéns, creches). Com efeito, focalizando o segmento de leite e derivados, Wilkinson e Mior (1999, p. 38) dizem tratar-se de "[...] um mundo de produção e consumo que combina produção própria, venda entre vizinhos e colocação em diversos pontos de vendas [...], muitas vezes como prolongamento de laços pessoais e de parentesco." Outro aspecto é que, além de serem opções para agricultores, essas práticas favorecem a continuidade de atividades tradicionais "enraizadas" no território, de índole histórica na região, como ressalta Dorigon (2010). Note-se ainda que, nessas investidas, que Mello e Schneider (2013) assimilam à busca de alternativas mediante a produção de "novidades", as pequenas cooperativas assim formadas interagem com diferentes agentes institucionais, como a Empresa de Pesquisa Agropecuária e Extensão Rural de Santa Catarina.

As tabelas 10, 11 e 12 fornecem uma ideia sobre a expansão desse tipo de atividade. As informações mostram a trajetória entre 1995 e 2015, para a Mesorregião Oeste Catarinense, do número de empregados formais e de estabelecimentos, por tamanho de estabelecimento, para atividades com realce nessa trajetória. Observe-se que, como a realidade produtiva abordada concerne primordialmente ao âmbito familiar, os dados - sobre trabalho formal - oferecem uma visão somente parcial do assunto. Ainda assim, mostram-se úteis, pois a agroindústria familiar também emprega mão de obra, como assinalam Kunzler e Badalotti (2014), entre outros. 
A tabela 10 ocupa-se do abate de aves e outros pequenos animais e preparação de produtos de carne. Observa-se estabilidade no número de estabelecimentos pequenos, de até 99 empregados, e algum crescimento nos de médio e grande porte. Quanto ao número de empregados, a presença nas unidades menores diminui, crescendo nas maiores (com exceção de uma categoria). A influência das grandes agroindústrias permaneceu forte: apesar dos investimentos em outras regiões brasileiras, a quantidade de empregados na faixa de mil ou mais foi ascendente em termos absolutos.

Tabela 10 - Mesorregião Oeste Catarinense: número de empregados formais e de estabelecimentos, por tamanho de estabelecimento, em abate de aves e outros pequenos animais e em preparação de produtos de carne - 1995-2015

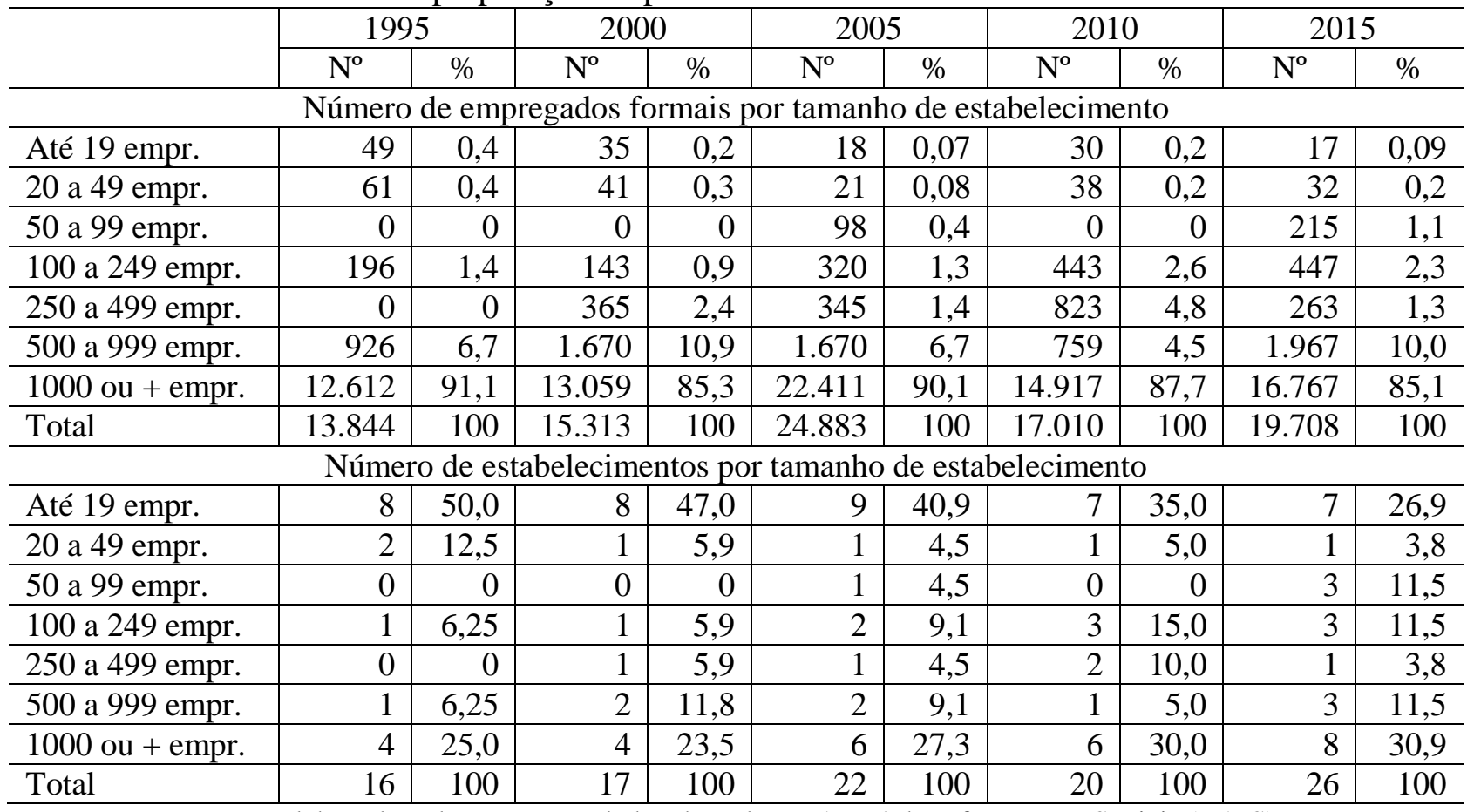

Fonte: elaborado pelo autor com dados da Relação Anual de Informações Sociais (RAIS) 〈http://bi.mte.gov.br/bgcaged/rais.php>

Obs.: os dados correspondem ao código 15121 da CNAE 95 Classe

A tabela 11 informa sobre as atividades de preparação de carne, banha e produtos de salsicharia não associada ao abate. Os dados não envolvem, portanto, as grandes empresas agroindustriais. Agroindústrias familiares rurais que produzem embutidos e outros itens baseados em carne encontram-se, de alguma forma, representadas. A quantidade de estabelecimentos cresceu consideravelmente até meados dos anos 2000, e depois caiu drasticamente entre os de menor ou maior porte, um movimento que repercutiu em termos de emprego. Embora se trate da 
esfera formal dessas atividades, sem que a tabela capte, portanto, a maior parte da realidade do trabalho nessas atividades - a mão de obra familiar há de prevalecer - , fica sugerida a presença de problemas, justificando medidas de apoio.

Tabela 11 - Mesorregião Oeste Catarinense: número de empregados formais e de estabelecimentos, por tamanho de estabelecimento, na preparação de carne, banha e produtos de salsicharia não associada ao abate - 1995-2015

\begin{tabular}{|c|c|c|c|c|c|c|c|c|c|c|}
\hline & \multicolumn{2}{|c|}{1995} & \multicolumn{2}{|c|}{2000} & \multicolumn{2}{|c|}{2005} & \multicolumn{2}{|c|}{2010} & \multicolumn{2}{|c|}{2015} \\
\hline & $\mathrm{N}^{\circ}$ & $\%$ & $\mathrm{~N}^{\circ}$ & $\%$ & $\mathrm{~N}^{\mathrm{o}}$ & $\%$ & $\mathrm{~N}^{\circ}$ & $\%$ & $\mathrm{~N}^{\mathrm{o}}$ & $\%$ \\
\hline \multicolumn{11}{|c|}{ Número de empregados formais por tamanho de estabelecimento } \\
\hline Até 19 empr & 36 & 3,1 & 30 & 1,9 & 103 & 7,5 & 13 & 6,0 & 12 & 3,9 \\
\hline 20 a 49 empr. & 44 & 3,8 & 0 & 0 & 83 & 6,0 & 68 & 31,3 & 20 & 6,5 \\
\hline 50 a 99 empr. & 52 & 4,5 & 80 & 5,2 & 0 & 0 & 136 & 62,7 & 171 & 55,5 \\
\hline 100 a 249 empr. & 0 & 0 & 0 & 0 & 202 & 14,7 & 0 & 0 & 105 & 34,1 \\
\hline 250 a 499 empr. & 0 & 0 & 406 & 26,2 & 412 & 29,9 & 0 & 0 & 0 & 0 \\
\hline 500 a 999 empr. & 0 & 0 & 0 & 0 & 576 & 41,9 & 0 & 0 & 0 & 0 \\
\hline $1000 \mathrm{ou}+\mathrm{empr}$. & 1.028 & 88,6 & 1.032 & 66,7 & 0 & 0 & 0 & 0 & 0 & 0 \\
\hline Total & 1.160 & 100 & 1.548 & 100 & 1.376 & 100 & 217 & 100 & 308 & 100 \\
\hline \multicolumn{11}{|c|}{ Número de estabelecimentos por tamanho de estabelecimento } \\
\hline Até 19 empr. & 5 & 62,5 & 9 & 75,0 & 22 & 81,5 & 5 & 55,5 & 3 & 42,9 \\
\hline 20 a 49 empr. & 1 & 12,5 & 0 & 0 & 2 & 7,4 & 2 & 22,2 & 1 & 14,3 \\
\hline 50 a 99 empr. & 1 & 12,5 & 1 & 8,3 & 0 & 0 & 2 & 22,2 & 2 & 28,6 \\
\hline 100 a 249 empr. & 0 & 0 & 0 & 0 & 1 & 3,7 & 0 & 0 & 1 & 14,3 \\
\hline 250 a 499 empr. & 0 & 0 & 1 & 8,3 & 1 & 3,7 & 0 & 0 & 0 & 0 \\
\hline 500 a 999 empr. & 0 & 0 & 0 & 0 & 1 & 3,7 & 0 & 0 & 0 & 0 \\
\hline $1000 \mathrm{ou}+$ empr. & 1 & 12,5 & 1 & 8,3 & 0 & 0 & 0 & 0 & 0 & 0 \\
\hline Total & 8 & 100 & 12 & 100 & 27 & 100 & 9 & 100 & 7 & 100 \\
\hline
\end{tabular}

Fonte: elaborado pelo autor com dados da Relação Anual de Informações Sociais (RAIS) <http://bi.mte.gov.br/bgcaged/rais.php>

Obs.: os dados correspondem ao código 15130 da CNAE 95 Classe

A tabela 12 informa sobre atividade de expressivo destaque, como sublinhado, entre as agroindústrias familiares rurais: a fabricação de produtos do laticínio. Os pequenos estabelecimentos, e mesmo os muito pequenos, são predominantes: entre 1995 e 2015, triplicou o número das unidades com até 19 empregados, representando 2/3 do total em 2015, e dobraram os situados na faixa de 20 a 49 empregados. Na esfera do emprego, contudo, a concentração transferiu-se progressivamente dos estabelecimentos de menor tamanho para os de média e grande dimensão: em 2015, 78\% estavam nas unidades entre cem e 999 empregados, muito mais que o dobro da participação em 1995. 
Tabela 12 - Mesorregião Oeste Catarinense: número de empregados formais e de estabelecimentos, por tamanho de estabelecimento, na fabricação de produtos do laticínio - 19952015

\begin{tabular}{|c|c|c|c|c|c|c|c|c|c|c|}
\hline & \multicolumn{2}{|c|}{1995} & \multicolumn{2}{|c|}{2000} & \multicolumn{2}{|c|}{2005} & \multicolumn{2}{|c|}{2010} & \multicolumn{2}{|c|}{2015} \\
\hline & $\mathrm{N}^{\mathrm{o}}$ & $\%$ & $\mathrm{~N}^{\mathrm{o}}$ & $\%$ & $\mathrm{~N}^{\mathrm{o}}$ & $\%$ & $\mathrm{~N}^{\mathrm{o}}$ & $\%$ & $\mathrm{~N}^{\mathrm{o}}$ & $\%$ \\
\hline \multicolumn{11}{|c|}{ Número de empregados formais por tamanho de estabelecimento } \\
\hline Até 19 empr. & 141 & 30,2 & 175 & 31,0 & 193 & 16,2 & 254 & 10,0 & 236 & 6,5 \\
\hline 20 a 49 empr. & 121 & 25,9 & 77 & 13,6 & 203 & 17,0 & 217 & 8,6 & 261 & 7,2 \\
\hline 50 a 99 empr. & 63 & 13,5 & 123 & 21,8 & 133 & 11,2 & 516 & 20,3 & 289 & 8,0 \\
\hline 100 a 249 empr. & 142 & 30,4 & 189 & 33,5 & 341 & 28,6 & 810 & 31,9 & 1.078 & 29,9 \\
\hline 250 a 499 empr. & 0 & 0 & 0 & 0 & 321 & 26,9 & 739 & 29,1 & 960 & 26,6 \\
\hline 500 a 999 empr. & 0 & 0 & 0 & 0 & 0 & 0 & 0 & 0 & 783 & 21,7 \\
\hline 1000 ou + empr. & 0 & 0 & 0 & 0 & 0 & 0 & 0 & 0 & 0 & 0 \\
\hline Total & 467 & 100 & 564 & 100 & 1.191 & 100 & 2.536 & 100 & 3.607 & 100 \\
\hline \multicolumn{11}{|c|}{ Número de estabelecimentos por tamanho de estabelecimento } \\
\hline Até 19 empr. & 16 & 72,7 & 27 & 81,8 & 31 & 70,4 & 43 & 67,2 & 49 & 66,2 \\
\hline 20 a 49 empr. & 4 & 18,2 & 3 & 9,1 & 8 & 18,2 & 7 & 10,9 & 8 & 10,8 \\
\hline 50 a 99 empr. & 1 & 4,5 & 2 & 6,1 & 2 & 4,5 & 7 & 10,9 & 5 & 6,8 \\
\hline 100 a 249 empr. & 1 & 4,5 & 1 & 3,0 & 2 & 4,5 & 5 & 7,8 & 8 & 10,8 \\
\hline 250 a 499 empr. & 0 & 0 & 0 & 0 & 1 & 2,3 & 2 & 3,1 & 3 & 4,0 \\
\hline 500 a 999 empr. & 0 & 0 & 0 & 0 & 0 & 0 & 0 & 0 & 1 & 1,4 \\
\hline $1000 \mathrm{ou}+$ empr. & 0 & 0 & 0 & 0 & 0 & 0 & 0 & 0 & 0 & 0 \\
\hline Total & 22 & 100 & 33 & 100 & 44 & 100 & 64 & 100 & 74 & 100 \\
\hline
\end{tabular}

Fonte: elaborado pelo autor com dados da Relação Anual de Informações Sociais (RAIS)

<http://bi.mte.gov.br/bgcaged/rais.php>

Obs.: os dados correspondem ao código 15423 da CNAE 95 Classe

Como nas outras atividades abordadas, o essencial do trabalho na cadeia do leite, realizado nas propriedades familiares, não está contemplado na tabela. Isso ganha ainda mais significado quando se observa que as respectivas atividades em Santa Catarina concentram-se em propriedades de até 50 hectares, segundo Santos, Marcondes e Cordeiro (2006). Mesmo assim, o que se apresenta sobre a fabricação de produtos do laticínio nesses dois decênios, com forte aumento da presença de estabelecimentos maiores, sugere mudanças em setor que emergiu como alternativa às adversidades provocadas pela reestruturação da agroindústria de carne.

Talvez isso decorra do marco regulatório introduzido no setor lácteo pela Instrução Normativa 51, editada em setembro de 2002 pelo Ministério da Agricultura, Pecuária e Abastecimento, em vigor desde julho de 2007. Representando restrições à participação de produtores não especializados, pelas exigências em tecnologia e outras, abrangendo produção, classificação, resfriamento, armazenagem e transporte, as novas regras logo suscitaram inquietações sobre a provável exclusão de propriedades incapazes de arcar com os elevados 
Revista Catarinense de Economia - RCE

APEC - Associação dos Pesquisadores em Economia Catarinense

1 ํㅡㄴ Semestre de 2017 - www.apec.pro.br/rce

custos da adequação, um problema que se anunciava e inquietava no oeste catarinense (FERRARI et al., 2005; OLIVEIRA; SILVA, 2012).

\subsection{Nota sobre ações de cunho institucional e iniciativas de movimentos sociais}

Importante atitude na promoção do desenvolvimento na região em foco refere-se ao Fórum de Desenvolvimento Regional Integrado (FDRI) da Associação dos Municípios do Oeste de Santa Catarina (AMOSC), que congregava numerosas entidades públicas e privadas com diferentes abrangências institucionais e espaciais. Um entre vários procedimentos observados na região, segundo Ferrari (2003), sua criação resultou do I Seminário sobre Planejamento e Desenvolvimento Regional, realizado em Chapecó em 1995 por conta dos problemas regionais, vistos como graves e exigentes de medidas coordenadas e eficazes. A resposta institucional representada pelo FDRI ganhou vigor com a criação do Instituto de Desenvolvimento Regional SAGA, seu braço operacional, para promover a integração das organizações sociais e econômicas da AMOSC, contribuir para políticas econômicas e sociais, planejar e executar estratégias de desenvolvimento regional e incentivar atividades econômicas.

O espírito das vinculadas iniciativas marca, de algum modo, a Carta de Chapecó, lançada no $1^{\circ}$ Encontro Internacional sobre Desenvolvimento Local e Sustentável, realizado em agosto de 2001 com participantes de vários países: “As identidades locais são reforçadas cada vez mais pelo fenômeno da globalização, e as regiões passam a ser o espaço territorial com escala para superação dos problemas e aproveitamento das oportunidades advindas do processo. (CARTA..., 2001, p. 1, grifo do autor). Mais: "Só há efetivo desenvolvimento se houver o DESENVOLVIMENTO NEGOCIADO. [...] A seleção natural darwiniana ou 'da luta' deve ser substituída pela promoção da ajuda mútua.” (CARTA..., 2001, p. 1, grifo do autor).

Os projetos promovidos pelo FDRI/SAGA implicaram diversas instituições e incluíram consórcio e tutela sobre produtos agrícolas regionais, marca regional para produtos agrícolas, observatório econômico, apoio a associações empresariais, incentivos a empresas e ações voltadas ao crédito e à capacitação profissional. Projeto especialmente bem sucedido, ao que parece, foi o relativo à marca regional para produtos agrícolas ou agropecuários, envolvendo disciplinares de produção a serem utilizados por agricultores e beneficiadores, individualmente ou em cooperativas, desde a produção primária até a transformação e comercialização. A observação das diretivas permite o uso da marca guarda-chuva regional Castalia, pertencente ao 
SAGA, em vários produtos da agroindústria familiar. Como indicado na página da instituição na internet, a produção e certificação de produtos orgânicos têm se destacado amplamente na sua atuação, embora outras ações sejam executadas (SAGA, 2017). Assim, seu papel no fortalecimento das agroindústrias rurais familiares tem sido muito importante, como reconhecido em livro editado pelo Banco Regional de Desenvolvimento do Extremo Sul (BRDE, 2004).

Cabe também assinalar que o raio de operações do FDRI/SAGA chegou a transcender os limites da AMOSC. A partir de 2001, ocorreu envolvimento no Programa de Desenvolvimento Integrado e Sustentável da Mesorregião Grande Fronteira do Mercosul, do governo federal, implicando 415 municípios de Santa Catarina, Rio Grande do Sul e Paraná. O convênio firmado entre o Ministério da Integração Nacional e o SAGA especificava que este se encarregaria em toda a área do apoio ao desenvolvimento turístico (TERMO DE CONVÊNIO..., 2001, p. 1). O SAGA fez convênio também com a Food and Agriculture Organization of the United Nations (FAO), para, sob os auspícios do Ministério da Integração Nacional, executar o Programa Organização Produtiva de Comunidades Pobres (PRONAGER) na Mesorregião Metade Sul do Rio Grande do Sul, e tornou-se responsável pela gerência e execução de projeto envolvendo agroindústrias rurais em toda a Mesorregião Grande Fronteira do Mercosul (GOEDERT, 2005).

Tal projeção foi muito significativa, justificando a classificação da estrutura FDRI/SAGA como uma experiência de realizações das mais notáveis em Santa Catarina, conforme sugerido por Birkner (2006), e como exemplo de efetiva cooperação entre organismos regionais (ABRAMOVAY, 2000). Todavia, como constatou Dias (2012) em estudo sobre as Secretarias de Desenvolvimento Regional (SDR) - carro chefe da gestão pública descentralizada adotada pelo governo catarinense desde 2003, tornadas Agências de Desenvolvimento Regional em 2016 - , o FDRI teve suas ações inibidas com esse novo modelo administrativo. A rigor, numa investida governamental que representou superposição de recortes regionais e favoreceu conflitos entre instituições e ações (DAMO, 2006), sem que um sistema descentralizado de planejamento e promoção do desenvolvimento realmente tivesse se efetivado em todo o estado (MIRANDA, 2012), o que o modelo das SDR efetuou foi tomar o lugar dos fóruns regionais (FILIPPIM; ABRUCIO, 2010). No âmbito da AMOSC, isso foi profundamente lamentado, em meio a considerações sobre o que o FDRI logrou realizar, conforme depoimentos coletados por Dias (2012). De toda maneira, o Instituto SAGA permaneceu em atividade. 
O Movimento dos Trabalhadores Rurais Sem Terra (MST) também protagonizou ações de cooperativismo-associativismo no oeste catarinense. Surgido no começo dos anos 1980, em maré montante contestatória cuja maior visibilidade recaiu, para Lisboa (1996), nas ocupações de terra e nos acampamentos e assentamentos, com resultados em produção e comercialização, o MST deparou-se continuamente com os problemas que costumam cercar a atuação e o cotidiano dos agricultores pobres, envolvendo sobretudo acesso a crédito e mercados. Daí a estratégia de cooperação agrícola em escala de movimento, permitindo-lhe sobressair em associativismocooperativismo no meio rural catarinense, particularmente na região oeste. Diversas associações de produtores foram criadas nos assentamentos, um processo alimentado por contribuições tanto dos serviços de extensão rural quanto dos sindicatos de trabalhadores rurais (SCHMIDT et al., 2002).

Em alguns casos ultrapassou-se largamente a órbita da sobrevivência, o objetivo mais urgente nos primeiros passos. Houve progressão rumo a estruturas representativas de maiores patamares de atuação econômica, sendo uma expressiva ilustração a experiência da Cooperativa Regional de Comercialização do Extremo-Oeste (Cooperoeste), criada em São Miguel do Oeste por famílias assentadas. Em meados dos anos 1990, com instalações e equipamentos financiados pelo Ministério da Reforma Agrária, a Cooperoeste criou a Laticínios Terra Viva, produzindo leite tipo $\mathrm{C}$, leite longa vida, bebidas lácteas, creme de leite e queijos, mobilizando centenas de agricultores - pela canalização de leite dos assentamentos - e representando dezenas de empregos diretos, ocupados primordialmente por filhos de pequenos agricultores.

Já nos seus primeiros anos, a Laticínios Terra Viva passou a ser divulgada como exemplo bem sucedido do que é possível fazer em assentamentos do MST, com mercado que transcendeu a escala regional e mesmo a estadual, sugerindo capacidade de concorrer com empresas de maior porte. Ajudaram no percurso realizações como o "[...] contrato de parceria com uma cooperativa uruguaia que produz 2,5 milhões de litro de leite por dia [...]. Foram oficializadas também parcerias com a Laticínios Cedrense e com a Cooperativa Regional Auriverde.” (EX-SEMTERRA..., 2002), estimulando outros assentamentos a se engajarem na industrialização de leite, com agregação de valor à produção primária de numerosos agricultores.

Atualmente, a marca Terra Viva Produtos da Reforma Agrária é estampada em dezoito produtos, que não se restringem ao leite e seus derivados e alcançam mercados nas regiões Sul e Centro Oeste do país (TERRA..., 2016). Observe-se que, pelo estudo de Anschau (2011) sobre 
cooperativas na área de leite presentes no oeste de Santa Catarina, a Laticínios Terra Viva é uma rede de perfil intermediário, entre vertical e horizontal: ao mesmo tempo em que opera em mercados competitivos, promove a diversificação produtiva nas propriedades rurais implicadas.

\section{Considerações finais}

Perante as transformações na atuação geral do Estado e as possibilidades ligadas às novas formas de organizar a produção, assim como os desafios impostos pelas mudanças econômicas recentes, não foram poucas as regiões nas quais, em vários países, procurou-se tomar as rédeas do futuro nas próprias mãos tentando promover o desenvolvimento. Em algumas houve mais êxito do que em outras, e as diferenças observadas constituem, em si, um instigante assunto. Os melhores resultados parecem derivar de uma elevada intensidade nas iniciativas e nos engajamentos, de uma maior capacidade para arregimentar forças em torno de objetivos mais ou menos comuns, com interações no nível local ou regional aptas a lidar com as adversidades e a sustentar a experimentação de alternativas.

Os conceitos de "enraizamento" e habitus, mencionados no texto, ajudam a pensar sobre esse último aspecto. Seus autores consideram a existência de uma razão prática - envolvendo, por exemplo, intencionalidade - que reflete a disposição dos agentes sociais, mas isto sempre ocorre sob a "coerção" de estruturas de relações plasmadas no curso da história. As iniciativas do FDRISAGA e do MST, referidas no trabalho, podem ser vistas por essa chave: é certo que denotaram vontade e capacidade de ação coletiva, mas o alcance e o perfil das ações refletiram as estruturas de relações nas quais os agentes implicados se inseriam. De algum modo, isso se traduziu na utilização, no oeste catarinense, da via representada pelas agroindústrias familiares rurais, em resistência às adversidades geradas pelas mudanças nas grandes agroindústrias de carne.

De toda maneira, diante de circunstâncias como essas, é sempre necessário avaliar as margens de manobra e os graus de liberdade disponíveis para iniciativas locais ou regionais, já que o peso dos movimentos mais amplos na esfera da economia é muito grande. A título de ilustração cabe referir ao estudo de Veiga e Rios (2016), segundo o qual a história da cadeia da carne de frango brasileira mostra avanços sucessivos em termos de internacionalização, com repercussões em vários de seus elos (pela imposição de padrões internacionais, entre outros aspectos). Indissociável de processos mais gerais na economia mundial, a mais recente etapa dessa longa trajetória implica instalar atividades de processamento em outros países: por 
Revista Catarinense de Economia - RCE

APEC - Associação dos Pesquisadores em Economia Catarinense

1을 Semestre de 2017 - www.apec.pro.br/rce

exemplo, no início de 2017 a Brasil Foods anunciou a compra da Banvit, líder no segmento de carne de frango na Turquia, país em que o consumo desse produto é alto (BRF..., 2017).

\section{Referências Bibliográficas}

ABRAMOVAY, R. O capital social dos territórios: repensando o desenvolvimento rural. Economia Aplicada, v. 4, n. 2, p. 379-397, 2000.

ALVES, J. M. de S.; WEYDMANN, C. L. Cadeia produtiva avícola. In: CARIO, S. A. F.; PANCERI, R.; FLAUSINO, E. S.; BITTENCOURT, M,; MONTIBELLER FILHO, G. CAVALCANTI, P. R. (Orgs.). Economia de Santa Catarina: inserção industrial e dinâmica competitiva. Blumenau: Nova Letra, 2008, p. 385-403.

ANSCHAU, C. T. Redes cooperativas da bovinocultura de leite e o desenvolvimento do oeste catarinense. 2011. 78 f. Dissertação (Mestrado em Ciências Ambientais) - Universidade Comunitária da Região de Chapecó, Chapecó, 2011.

ASSIS, F. O.; MURATORI, A. M. Poluição hídrica por dejetos de suínos: um estudo de caso na área rural do município de Quilombo, Santa Catarina. Geografar, v. 2, n. 1, p. 42-59, jan./jun. 2007. Obtido em: www.ser.ufpr.br/geografar Acesso em: 10 jan. 2017.

BELUSSO, D.; HESPANHOL, A. N. A evolução da avicultura industrial brasileira e seus efeitos territoriais. Revista Percurso - NEMO, v. 2, n. 1, p. 25-51, 2010.

BIRKNER, W. M. K. Capital social em Santa Catarina: o caso dos fóruns de desenvolvimento regional. Blumenau: Edifurb, 2006.

BOURDIEU, P. Le champ économique. Actes de la Recherche en Sciences Sociales, Paris, n. 119, p. 4866, Sep. 1997.

BOURDIEU, P. L'essence du néoliberalisme. Le Monde Diplomatique, n. 528, p. 3, Mars 1998.

BOURDIEU, P. O poder simbólico. $5^{\text {a }}$ ed. Rio de Janeiro: Bertrand Brasil, 2002.

BRASIL. Constituição da República Federativa do Brasil de 1988 . Disponível em: http://www.planalto.gov.br/ccivil 03/constituicao/constituicao.htm Acesso em: 06 fev. 2016.

BRDE - BANCO REGIONAL DE DESENVOLVIMENTO DO EXTREMO SUL. Redes de agroindústrias de pequeno porte: experiências de Santa Catarina. Florianópolis: BRDE, 2004.

BRF compra a líder em carne de frango na Turquia. Diário Catarinense, p. 13, 10 jan. 2017.

BUAINAIN, A. M. (Coord.). Agricultura familiar e inovação tecnológica no Brasil: características, desafios e obstáculos. Campinas: Editora da Unicamp, 2007.

CABRAL, O. R. História de Santa Catarina. Florianópolis: Imprensa da Universidade Federal de Santa Catarina, 1968.

CARACTERIZAÇÃO e tendências da rede urbana do Brasil. V. 6 - Redes urbanas regionais: Sul. Brasília: IPEA, 2000.

CARNEY, J.; HUDSON, R.; LEWIS, J. (Eds.). Regions in crisis: new perspectives in European regional theory. London: Croom Helm, 1980.

CARTA de Chapecó. I Seminário Internacional sobre Desenvolvimento Local e Sustentável, Fórum Catarinense de Desenvolvimento, Chapecó, UNOESC, SBT/SC, SEBRAE Nacional, ago. 2001.

CARVAlHO JÚNIOR., L. C. de; CARIO, S. A. F.; SEABRA, F. Polos industriais do sul do Brasil: experiências de competitividade e empreendedorismo. Parte I. Florianópolis: [S.n.], 2007.

COLETTI, T.; LINS, H. N. A suinocultura no vértice das relações ebtre agroindústria e agricultura familiar no oeste de Santa Catarina. Ensaios FEE, v. 32, n. 2, p. 339-360, nov. 2011.

DAMO, M. R. S. Análise da descentralização administrativa do governo do estado e os efeitos da fragmentação territorial no oeste catarinense. 2006. 205 f. Dissertação (Mestrado em Engenharia Civil) - Universidade Federal de Santa Catarina, Florianópolis, 2006.

DIAS, T. Governança pública: uma concepção teórico-analítica aplicada no governo do Estado de Santa Catarina a partir da implantação das Secretarias de Desenvolvimento Regional. 2012. 356 f. Tese (Doutorado em Administração) - Universidade Federal de Santa Catarina, Florianópolis, 2012. 
DORIGON, C. O mercado informal dos produtos coloniais da região oeste de Santa Catarina. In: VI ENCONTRO NACIONAL DE ESTUDOS DO CONSUMO/I ENCONTRO LUSO-BRASILEIRO DE ESTUDOS DO CONSUMO, Rio de Janeiro, 15-17 set. 2010. Anais... [S.p.].

ESPÍNDOLA, C. J. As agroindústrias do oeste catarinense: o caso Sadia. 1996. 309 f. Dissertação (Mestrado em Geografia) - Universidade de São Paulo, São Paulo, 1996.

ESPÍNDOLA, C. J. As agroindústrias de carne do sul do Brasil. 2002. 261 f. Tese (Doutorado em Geografia) - Universidade de São Paulo, São Paulo, 2002.

ESSER, J., HIRSCH, J. The crisis of fordism and the dimension of a "post-fordist" regional and urban structure. International Journal of Urban and Regional Research, v.13, n. 3, p. 417-437, 1989.

EX-SEM-TERRA exportam leite para Uruguai. A Notícia, [S.p], 15 jun. 2002. Obtido em www.an.com.br/2002/jun/15/0eco.htm. Acesso em 5 dez. 2003.

FERRARI, D. L. Agricultura familiar, trabalho e desenvolvimento no oeste de Santa Catarina. 2003. 190 f. Dissertação (Mestrado em Desenvolvimento Econômico, Espaço e Meio ambiente) Universidade Estadual de Campinas, Campinas, 2003.

FERRARI, D. L.; MELLO. M. A. de; TESTA, V. M.; SILVESTRO, M. L. Agricultores familiares, exclusão e desafios para inserção econômica na produção de leite em Santa Catarina. Informações Econômicas, v. 35, n. 1, p. 22-36, jan. 2005.

FILIPPIM, E.; ABRUCIO, F. L. Quando descentralizar é concentrar poder: o papel do governo estadual na experiência catarinense. Revista de Administração Contemporânea, v. 14, n. 2, p. 212-228, mar./abr. 2010.

FLORES, M. B. R.; SERPA, E. C. A hermenêutica do vazio: fronteira, região e brasilidade na viagem do governador ao oeste de Santa Catarina. Projeto História, v. 18, p. 215-235, maio 1999.

FUJITA, C.; MAIA, C. M.; ALBA, R. S. Reestruturação produtiva e dinâmica urbana e regional no oeste catarinense: uma análise do papel de Chapecó e outras cinco cidades influentes. In: XV ENCONTRO NACIONAL DA ANPUR, Recife, 20 a 24 maio 2013. Obtido em: www.unuhospedagem.com.br/revista/rbeur/index.php/anais/article/view/4336 Acesso em: 14 jan. 2017.

GAROFOLI, G. Economic development, organization of production and territory. Revue d'Economie Industrielle, n. 64, p. 22-37, $2^{\circ}$ trimestre 1993.

GOEDERT, A. R. Governança em rede de desenvolvimento e a experiência de Santa Catarina. 2005. 446 f. Tese (Doutorado em Engenharia de Produção) - Universidade Federal de Santa Catarina, Florianópolis, 2005.

GOULARTI FILHO, A. Formação econômica de Santa Catarina. Florianópolis: Cidade Futura, 2002.

GRANOVETTER, M. Economic action and social structure: the problem of embeddedness. American Journal of Sociology, v. 91, n. 3, p. 481-510, Nov. 1985.

HELFAND, S. M.; REZENDE, G. C. Mudanças na distribuição espacial da produção de grãos, aves e suínos no Brasil: o papel do Centro-Oeste. Planejamento e Políticas Públicas, n. 611, p. 219-273, 1999.

IBGE - INSTITUTO BRASILEIRO DE GEOGRAFIA E ESTATÍSTICA. Censo Demográfico 1991. Resultados do Universo - Santa Catarina. Obtido em: http://biblioteca.ibge.gov.br/visualizacao/periodicos/82/cd 1991 n23 caracteristicas populacao domi cilios_sc.pdf Acesso em: 05/01/2017.

IBGE - INSTITUTO BRASILEIRO DE GEOGRAFIA E ESTATÍSTICA. Censo Demográfico 2000. Resultados do Universo. Obtido em: ftp://ftp.ibge.gov.br/Censos/Censo_Demografico_2000/Dados_do_Universo/Meso_Microregioes_Distr itos_Subdistritos_Bairros/ Acesso em: 05/01/2017.

IBGE - INSTITUTO BRASILEIRO DE GEOGRAFIA E ESTATÍSTICA. Regiões de influência das cidades 2007. Rio de Janeiro: IBGE, 2008.

IBGE - INSTITUTO BRASILEIRO DE GEOGRAFIA E ESTATÍSTICA. Censo Agropecuário 2006. Rio de Janeiro: IBGE, 2009. 
Revista Catarinense de Economia - RCE

APEC - Associação dos Pesquisadores em Economia Catarinense

1ํㅗ Semestre de 2017 - www.apec.pro.br/rce

IBGE - INSTITUTO BRASILEIRO DE GEOGRAFIA E ESTATÍSTICA. Censo Demográfico 2010. Resultados do Universo. Obtido em: http://www.ibge.gov.br/home/estatistica/populacao/censo2010/caracteristicas_da_populacao/caracterist icas da populacao tab municipios zip xls.shtm Acesso em: 05/01/2017.

KUNZLER, L. L.; BADALOTTI, R. M. Bases e importância da agroindústria familiar rural no oeste catarinense. In: 2. SEMINÁRIO NACIONAL DE PLANEJAMENTO E DESENVOLVIMENTO, Florianópolis, Universidade do Estado de Santa Catarina, 16 a 19 set. 2014. Anais... [S.p.].

LAZZARI, M. R. Avicultura de corte no Brasil: uma comparação entre as Regiões Sul e Centro-Oeste. Indicadores Econômicos FEE, v. 31, n. 4, p. 259-290, 2004.

LINS, H. N.; GOULART, G. T. Novos espaços de atuação do grande capital agroalimentar: a agroindústria de carnes no sudoeste de Goiás (Brasil). In: VIII JORNADAS INTERDISCIPLINARIAS DE ESTUDIOS AGRARIOS Y AGROINDUSTRIALES, Buenos Aires, 29 out. a 1 nov. 2013, Universidad de Buenos Aires, Facultad de Ciéncias Económicas. Anais..., p. 1-20.

LIPIETZ, A. Du développement local au développement durable. Territoires, n. 431, Oct. 2002.

LISBOA, T. K. A luta dos sem terra no oeste catarinense. Katalysis, v. 1, p. 104-127, 1996.

MELLO, M. A. de; SCHNEIDER, S. A produção de "novidades" como alternativa à crise pelos agricultores do oeste de Santa Catarina. Desafio Online, v. 1, n. 3, p. 1-18, set./dez. 2013. Obtido em: www.desafioonline.com.br Acesso em: 12 jan. 2017.

MIRANDA, E. Descentralização e territorialização do sistema de planejamento do desenvolvimento em Santa Catarina: uma análise sistêmica do período 2003-2010. 2012. 220 f. Tese (Doutorado em Sociologia Política) - Universidade Federal de Santa Catarina, Florianópolis, 2012.

MIOR, L. C. Agricultores familiares, agroindústrias e redes de desenvolvimento rural. Chapecó: Argos, 2005.

MORGAN, K. The learning region: institutions, innovation and regional renewal. Regional Studies, v. 31, n. 5, p. 491-503, 1997.

MOULAERT, F., SWYNGEDOUW, E., WILSON, P. Spatial responses to fordist and post-fordist accumulation and regulation. Papers of the Regional Science Association, v. 64, p. 11-23, 1988.

OESTE Catarinense - Programa Nacional de Desenvolvimento Sustentável de Territórios Rurais. Plano Territorial de Desenvolvimento Rural Sustentável (PTDRS). Brasília: Secretaria de Desenvolvimento Territorial/Ministério do Desenvolvimento Agrário, nov. 2010.

OLIVEIRA, L. F. T.; SILVA, S. P. Mudanças institucionais e produção familiar na cadeia produtiva do leite no oeste catarinense. Revista de Economia e Sociologia Rural, v. 50, n. 4, p. 705-720, out./dez. 2012.

PAIM, E. A. Aspectos da construção histórica da região oeste de Santa Catarina. SFCULUM - Revista de História, v. 14, p. 121-138, jan./jun. 2006.

PIORE, M., SABEL, C. F. The second industrial divide: possibilities for prosperity. New York: Basic Books, 1984.

PLEIN, C. A modernização da agricultura brasileira e seus efeitos sobre a agricultura familiar no oeste catarinense. Faz Ciência, v. 8, n. 1, p. 35-72, 2006.

POLI, O. L. Cultura e modo de vida camponês no oeste catarinense: as bases para a organização e reação frente à crise dos anos 70. Cadernos do CEOM, v. 16, n. 5, p. 107-175, jun. 2002.

ROSSETTO, S. Síntese histórica da região Oeste. Cadernos do CEOM, v. 1, n. 1, p. 7-15, 1986.

SAGA. O Instituto de Desenvolvimento Regional - SAGA tem focado seus trabalhos na produção e certificação de produtos orgânicos. Chapecó: SAGA, 2017. Obtido em: http://www.institutosaga.org.br/ Acesso em: 18 jan. 2017.

SANTOS, O. V.; MARCONDES, T.; CORDEIRO, J. L. F. Estudo da cadeia do leite em Santa Catarina: prospecção e demandas. Florianópolis: EPAGRI/CEPA, 2006.

SANTOS FILHO, J. I. dos; SANTOS, N. A. dos; CANEVER, M. D.; SOUSA, I. S. F. de; VIEIRA, L. F. O cluster suinícola do Oeste de Santa Catarina. In: HADDAD, P. R. (Org.). A competitividade do agronegócio e o desenvolvimento regional no Brasil: estudos de clusters. Brasília: CNPq/EMBRAPA, 1999, p. 125-180. 
SCHMIDT, W.; TURNES, V. A.; CAZELLA, A. A.; SCHMIDT, V. B,; GELBCKE, D. Associativismo e cooperativismo: o terceiro setor no desenvolvimento rural catarinense. In: VIEIRA, P. F. (Org.). A pequena produção e o modelo catarinense de desenvolvimento. Florianópolis: APED Editora, 2002, p. 59-110.

SCHMITZ, H. Collective efficiency: growth path for small-scale industry. The Journal of Development Studies, v. 31, n. 4, p. 529-566, Apr. 1995.

SILVA, C. L.; BASSI, N. S. S. Análise dos impactos ambientais no Oeste Catarinense e das tecnologias desenvolvidas pela Embrapa Suínos e Aves. In: VI ENCONTRO NACIONAL DA ASSOCIAÇÃO NACIONAL DE PÓS-GRADUAÇÃO E PESQUISA EM AMBIENTE E SOCIEDADE (ANPPAS), Belém, 18121 set. 2012. Anais..., p. 1-17.

SILVA, A. da; ROSA, A. da. Antes do Oeste Catarinense: Aspectos da vida econômica e social de uma região. Fronteiras: Revista Catarinense de História, n. 18, p. 139-160, 2010.

TERMO DE CONVÊNIO que entre si celebram a União, pelo Ministério da Integração Nacional/MI, por intermédio da Secretaria de Programas Regionais Integrados, e o SAGA Instituto de Desenvolvimento Regional, para o fim que especifica. Brasília, Ministério da Integração Nacional/Secretaria de Programas Regionais Integrados, 2001. (Processo No 59000.005371/2001-10).

TERRA Viva Produtos da Reforma Agrária: Institucional. São Miguel do Oeste: Cooperoeste, 2016. Obtido em: http://www.terravivasc.com.br/site/institucional Acesso em: 18 jan. 2017.

TESTA, V. M.; NADAL, R.; MIOR, L. C.; BALDISSERA, I. T.; CORTINA, M. O desenvolvimento sustentável do Oeste Catarinense (proposta para discussão). Florianópolis: EPAGRI, 1996.

TESTA, V. M.; MELLO, M. A. de; FERRARI, D. L.; SILVESTRO, M. L.; DORIGON, C. A escolha da trajetória da produção de leite como estratégia de desenvolvimento do Oeste Catarinense. Florianópolis: Governo do Estado de Santa Catarina/Secretaria da Agricultura e Política Rural, 2003.

THEIS, I. M., NODARI, T. M. dos S. A agroindústria de aves e o desenvolvimento regional no Meio Oeste de Santa Catarina. Cadernos de Economia, v. 4, n. 7, p. 7-28, jul.-dez. 2000.

VÁZQUEZ BARQUERO, A. Desenvolvimento endógeno em tempos de globalização. Porto Alegre: Fundação de Economia e Estatística; Editora da UFRGS, 2001.

VEIGA, P. da M.; RIOS, S. P. Cadeias de valor baseadas em recursos naturais: o caso do Brasil. Textos para Discussão/IPEA, n. 2173, Brasília: IPEA, fev. 2016.

WEYDMANN, C. L.; ALVES, J. M. de; PINTO, J. P. de M.; ALMEIDA, G. P. de. Cadeia produtiva suinícola. In: CARIO, S. A. F.; PANCERI, R.; FLAUSINO, E. S.; BITTENCOURT, M,; MONTIBELLER FILHO, G. CAVALCANTI, P. R. (Orgs.). Economia de Santa Catarina: inserção industrial e dinâmica competitiva. Blumenau: Nova Letra, 2008, p. 509-536.

WILKINSON, J. Os gigantes da indústria alimentar entre a grande distribuição e os novos clusters a montante. Estudos Sociedade e Agricultura, v. 18, p. 147-174, abr. 2002.

WILKINSON, J.; MIOR. L. C. Setor informal, produção familiar e pequena agroindústria: interfaces. Estudos Sociedade e Agricultura, v. 13, p. 29-45, out. 1999. 